\title{
Game Analysis on Profits of Water Diversion Project Supply Chain Under the Overall Loss of Supply Chain in Undeveloped Areas
}

\author{
Jinren LUO, Jiayin LI ${ }^{1}$, Qinyao FU, Yihu ZHAO, Shan LIU \\ Institute of Economics and Management, Lanzhou Jiaotong University, Lanzhou, \\ Gansu, 730070, China
}

\begin{abstract}
This paper compares and analyzes the effects of different amounts of government subsidies and subsidy patterns on water supply, pricing, and profit distribution, and takes water diversion project supply chain composed of water transfer company and the water work as the study object, using financial accounting method innovatively, establishing non-cooperative and cooperative game models of two under government subsidies. The results show that as the number of subsidies increased, the optimal amount of water supply and the profits increased, but the price of water work decreased. When the amount of subsidy stays same, the price of water plant also stays same. However, the price of the water transfer company is constantly changing, the higher the proportion of subsidies it received, the lower the price. In terms of data, the authors take a practical example - the Tao River Water Diversion Project to analyze. This paper's limitation is that the conclusion is based on a single water transfer company and a single water plant as the research object. However, the actual situation of the water transfer project is that a water transfer company faces a complex supply chain network formed by many water plants and farmers' water users' associations.
\end{abstract}

Keywords. The supply chain of water diversion project in undeveloped areas, government subsidies, non-cooperative game, cooperative game, Shapley Value

\section{Introduction}

Water diversion project is an effective measure to solve the problem of highly uneven distribution of water resources in the world. With the development of various national undertakings, cross-regional water transfer projects are increasing in China. South to North Water Division Project, Yellow River to Qinghai Water Division Project, and Tao River Water Division Project are based on multi-objective water supply, serving urban industry and considering agriculture and environment, which are both operating and public welfare. In terms of the situation that the affordability of water price in some underdeveloped areas cannot even make up for the project operation cost, it is necessary to consider the government subsidy under the premise of considering the public welfare

${ }^{1}$ Corresponding Author: Jiayin Li, Institute of Economics and Management, Lanzhou Jiaotong University, Lanzhou, Gansu, 730070, China; E-mail: 1948858040@qq.com

This work is supported by National Natural Science Foundation of China [71463036]: Benefit Balance Mechanism of Stakeholders with Multi-objective Trans-water Project Between Less Developed Regions. 
of the project and the water price born by users. How can government subsidies be introduced to balance the interests of enterprises in the water transfer project supply chain in underdeveloped areas to maintain sustainable water supply has become an important research topic.

Domestic and foreign scholars have obtained numerous research results on the issue of government subsidies in the supply chain. Their research focuses mainly on the effects of subsidies, subsidy objects, and subsidy weight, and the game is the major method. The effects of subsidies and subsidy objects are studied mostly from the qualitative perspective. T.G. Mallory [1] assessed the causation and effectiveness of Chinese government fishery subsidies and the effects of government subsidies on fisheries. L.H. He and L.Y. Chen [2] studied the incentive effects of four different government subsidy policies in the green construction market. D. McQuestin and M. Noguchi [3] analyzed the effectiveness of government subsidies in the emergency waiting of local health network systems. Frye and Shleifer(1997) pointed out that in the transitional economy, subsidies are the most direct means for the government to play a 'helping hand' role. [4] R.C. Hu et al. [5] studied the application effect of government subsidies at the provincial and industrial levels. H.J. Wang et al. [6] studied the government's preference to subsidize enterprises with serious losses (poor behavior) or enterprises with light losses (emergency behavior) and their economic consequence from the perspective of property rights nature, regional government intervention degree, and industry competition degree. D.M. Kong and T.Sh. Li [7] investigated the effects of government subsidies on enterprises with different property rights from the perspective of business performance and social responsibility. Ch.S. Wu et al. [8] studied the effects of government subsidies on business performance from the political connection perspective. Q. Geng and R.X. $\mathrm{Hu}$ [9] believed that the probability and degree of enterprises obtaining subsidies are affected by their endowment and nature. Generally speaking, Chinese government subsidies have an obvious state-owned preference, scale preference, export preference, and industry tendency.

Many scholars use game theory to study the supply chain weight. Q. Wu et al. [10] used the core method of the cooperative game and established the mix-integer linear programming model to achieve fair benefit distribution among participants in the distributed energy network. M. Babaei et al. [11] proposed that government subsidies to investors and control the number of intermediaries can promote investors to earn profits, which is supported by Stackelberg game theory. Q.H. Zhu and Y.J. Dou [12] established a three-stage game model that considers the green degree of products and government subsidies in the green supply chain. H.X. Lu [13] constructed a Stackelberg decentralized decision model and centralized decision model of the supply chain under government subsidies and analyzed the effects of the changes in government subsidies on pricing decisions. Y.D. Li et al. [14] constructed a game model in which the government subsidizes the cooperative emission reduction investment of the low-carbon supply chain under three different game relationships: Nash game, Stackelberg game, and centralized decision-making of supply chain. They also analyzed the optimal emission reduction cost of the supply chain and the optimal subsidy rate of the government. X.L. Zhang and J.J. Wang [15] used the Shapley value method to study the impact of government subsidies on supply chain decision-making in the new energy vehicle supply chain.

In the existing research results, many analyses of the game relationship between water transfer companies and tap water plants can be found. For example, H.M. Wang et al. [16] and Zh.S. Chen [17] established some interesting game models and analyzed the relationship between water transfer companies and tap water plants in the water supply 
chain. Some scholars also analyzed the relationship between the supply chain of water division projects and government subsidies from the theoretical perspective. L.Zh.Wu et al. [18] explored the multi-objective reservoir optimal operation model and carried out inter-basin water transfer under the consideration of the benefits contradiction between environmental and economic. X.Zh. Wang and Y.R. Wang [19] considered the public welfare of the South to North Water Division Project and the affordability of water price users, analyzed the reasonable water price composition of the project, and studied the water price subsidy policy. J.R.Luo [20] calculated the affordable water price of different water used in the Tao River Division Project and put forward the suggestion of government subsidy for agricultural water with low bearing capacity.

Academic circles have demonstrated the importance of government subsidies for economic development and studied government subsidies objects, weight in the supply chain by the method of game. These studies have some guiding significance for the current interest coordination management of water supply project's supply chain, but there are still some shortcomings: most studies are limited to the theoretical models. Because the model is not integrated with the specific financial accounting information, the parameters of the models are difficult to determine, which leads to the poor guidance of the established mathematical model. The research on the subsidy of inter-basin water transfer projects is not mature, and limited research has focused on the subsidy of the water resource supply chain.

Given the above considerations, this paper intends to use the financial accounting method to establish a two-level supply chain interest game model composed of water transfer companies and water plants (including farmers' water users' associations) participated by the government, and analyze the effects of different government subsidy amount and subsidy mode on water supply quantity, pricing, and profit distribution of water transfer companies and waterworks. The data of the Tao River Division Project will be used to analyze the case.

\section{Description of the Basic Concept}

\subsection{Method of Shapley Value}

In 1953, Shapley proposed the Shapley value method to solve the problem of profit distribution in multi-person cooperative games. When $n$ individuals are engaged in economic activity, each form of cooperation among several of them will produce certain benefits. When the interest activities between people are non-antagonistic, the increase in the number of people in cooperation will not cause a decrease in income, then the cooperation of all $n$ individuals will bring the maximum benefit. In other words, when $n$ individuals form an alliance, they will obtain the maximum benefit. The Shapley value method is a scheme to redistribute the maximum income among participants. Its connotation is as follows: Let set $I:\{1,2, \ldots, n\}$ if any subset $X$ (representing any combination in the set of $n$ people, also known as a coalition)of $I$ corresponds to a realvalued function, $v(X)$ satisfying the

$$
\begin{gathered}
v(\phi)=0 \\
v\left(X_{1} \cup X_{2}\right) \geq v\left(X_{1}\right)+v\left(X_{2}\right), X_{1} \cap X_{2}=\phi
\end{gathered}
$$


Then the $[I, v]$ is called $n$ people cooperation countermeasures, where $v$ is the characteristic function of cooperative countermeasures. In this paper, we use $\varphi_{i}(v)$ to denote $i_{\text {members' income allocated by }} I_{\text {members from the maximum profit }} v(I)$ of cooperation. The set of the allocation of $n$-person cooperative countermeasures is $\psi(v)=\left(\varphi_{1}(v), \varphi_{2}(v), \Lambda, \ldots \varphi_{\mathrm{n}}(v)\right)$. The success of cooperation must satisfy the following conditions:

$$
\sum_{i=1}^{n} \phi_{i}(v)=v(I), \text { and } \phi_{i}(v) \geq v(i), i=1,2, \ldots n
$$

The profit distribution of each partner under cooperation $I$ is called the Shapley value. The expression of Shapley value is as follows:

$$
\varphi_{i}(v)=\sum_{X \subseteq N} \frac{(|X|-1) !(n-|X|) !}{n !}[v(X)-v(X-\{i\})], \forall i \in N
$$

This expression $\varphi_{i}(v)$ represents the Shapley value of the ith member in the supply chain. $\mid X_{\mid}$is the number of members in the $X$ subset, $n$ is the total number of members in the supply chain, $v(X)$ is the profit value of the $X$ supply chain subset, and $v(X-\{i\})$ is the $i_{\text {profit value not included in the }} X$ supply chain subset.

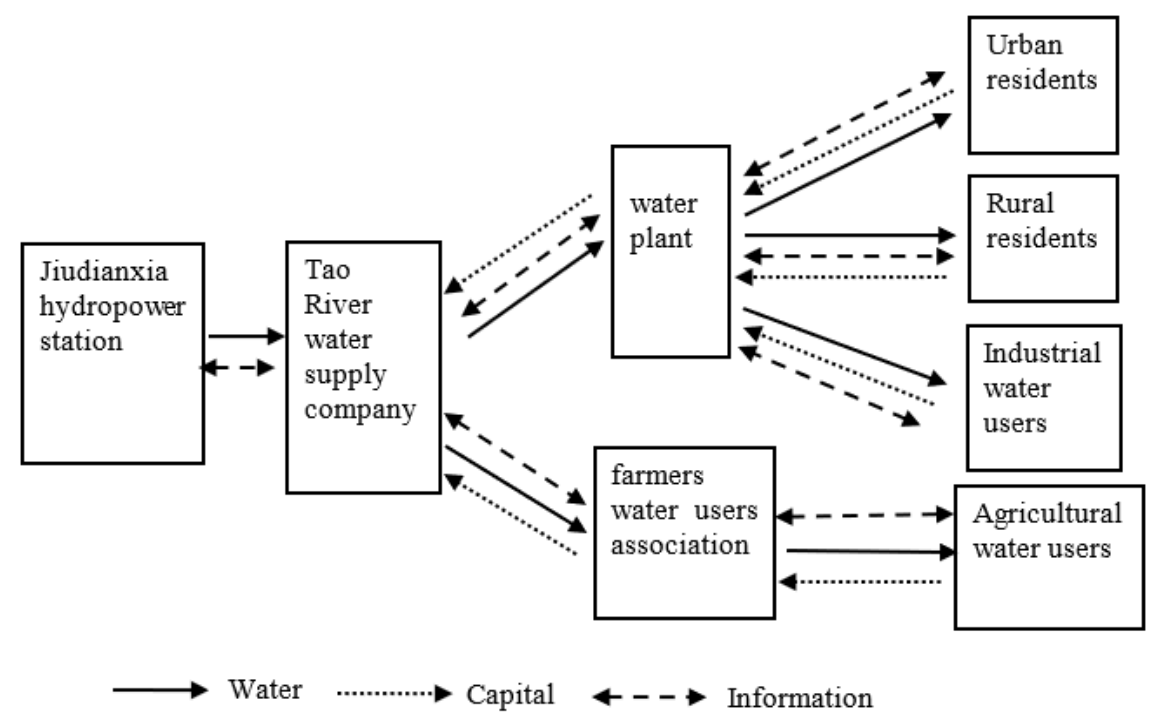

Figure 1. Water Resources Supply Chain of Tao River Diversion Project.

\subsection{Water Resources Supply Chain Diagram of Water Transfer Project}

Water Division Project refers to the water diversion system composed of hydro-junction, net pipe, and pumping station. Taking the Taohe River Division Project as an example, the water resources supply chain of the water diversion project is a complex network system [21]. In this system, the water flows down from the Jiudianxia hydropower 
station to the users in the receiving area, and the fund flows upward from the users in the receiving area to the water division company of Tao River. The supply and demand information flows in two directions in the entire chain. The schematic diagram is shown in Figure 1.

\section{Game Analysis of Supply Chain Benefits Under the Premise of The Overall Loss of Water Transfer Project Supply Chain}

\subsection{Model Analysis}

Limited by the level of economic development, the affordability of water prices in underdeveloped areas is generally low, and the affordability of different water use categories also differ. Taking the Tao River Diversion Project as an example, the bearing capacity of domestic water of rural and urban areas and industrial water is greater than the full cost of the supply chain. While the bearing of agricultural water is far lower than the cost of the supply chain, it cannot make up for the operation cost of the water transfer company. [21] In the view of the later situation, this paper explores how the losses can be shared between water transfer companies and waterworks, and how it can be subsidized by the government to maintain the normal operation of the water diversion supply chain.

The total cost of the water transfer project supply chain can be divided into two parts: fixed cost and variable cost. Because fixed cost (formed mainly by fixed assets invested by state) has become a sunk cost, it will happen even no water supply can be found. The variable cost will be put into the case of water supply. For the node enterprises, whether water supply or waste use depends on whether their variable costs can be compensated. If $V_{m}$ and $V_{r}$ are used to represent the unit variable cost of the water transfer company and water plant, respectively, $Q$ is the market demand for water supply, $p$ is the water price of the water plant. When the fixed cost is not considered $\pi_{m}$ and $\pi_{r}$ is used to represent the income of the water transfer company and the water plant respectively. The income matrix of both parties is shown in Table 1.

Table 1. Income matrix 1 of water transfer companies and waterworks.

\begin{tabular}{|c|c|c|c|}
\hline & Water works & & \\
\hline \multirow{3}{*}{ Water transfer company } & strategy & water use & no water use \\
\hline & water supply & $\pi_{m}, \pi_{r}$ & $-V_{m} Q, 0$ \\
\hline & no water supply & $0,-V_{r} Q$ & 0,0 \\
\hline
\end{tabular}

In the case of $p<V_{m}+V_{r}, \pi_{m}+\pi_{r}=p Q-\left(V_{m}+V_{r}\right) Q<0$, that is, if the water price of the waterworks is lower than the sum of the variable costs of the water diversion company and water plant, regardless of the rules that the two sides use to distribute profits, there must be at least one sides' income being negative, and the party with a negative income will inevitably choose the strategy of no water supply or no water use. Thus, the best strategy of the other party at this time will be no water use or no water supply. Therefore, the optimal strategy combination for both sides is (no water supply, no water use), and the revenue is 0 , which is a typical Nash equilibrium. 
The water transfer projects with public welfare in underdeveloped areas requires that government subsidies should be considered, which makes water division companies and water plants willing to choose the strategic combination (water supply, water use). Without considering the fixed cost, if the subsidy is less than the loss of the variable cost of the supply chain, it means at least one party's income is negative after the subsidy, and two sides will choose the (no water supply, no water use) strategy combination. However, previous research on the subsidies shows that more subsidies are not better. On the contrary, it may reduce the operating efficiency of the supply chain. The best strategy is that the subsidy amount is exactly equal to the total variable cost loss, and the variable cost loss of the water transfer company and water plant is just compensated. The income matrix of both parties is shown in Table 2 .

Table 2. Income matrix 2 of water transfer companies and waterworks.

\begin{tabular}{llll}
\hline & Water works & & \\
\hline & strategy & water use & no water use \\
Water transfer company & water supply & 0,0 & $-V_{m} Q, 0$ \\
& no water supply & $0,-V_{r} Q$ & 0,0
\end{tabular}

At this time, although many equilibrium solutions can be obtained in theory, considering the role of government and cooperation of social responsibility, we can see that the optimal strategy combination for both sides is (water supply, water use), which is beneficial to the three parties.

\subsection{Model Hypothesis and Variable Description}

\subsubsection{Model Hypothesis}

First, the game participants include the government, water transfer companies, and waterworks (including farmers' water users' association). Because the government only plays a regulatory role, the specific game is only between the water transfer company and the water plant, both of which are bounded, rational economic men.

Second, the government's strategy set is \{all subsidies, subsidies only to water transfer companies, subsidies only to waterworks, no subsidies $\}$, the strategy set of water transfer companies is \{water supply, no water supply\}, and the strategy set of waterworks is \{water use, no water use\}. After the government subsidies are added, the decisionmaking order is the government $\rightarrow$ water transfer company $\rightarrow$ water plant.

Third, no other source of water for the waterworks other than the water diversion company can be found.

Fourth, the demand for tap water is a decreasing function of the retail price, and the demand function is as follows:

$$
Q=Q_{0}-\alpha P
$$

In other words, $Q_{0}$ represents the maximum market demand and $\alpha$ is the sensitivity coefficient of sales volume to the price of tap water, $\alpha>0, Q>0, Q_{\text {is equal to the }}$ water production, water supply of the water transfer company, and the water plant. 


\subsubsection{Model solution}

This paper calculated the incomplete cost of water transfer company and waterworks according to the method of financial accounting after deducting the depreciation of fixed assets and dividing them into unit incomplete cost according to the volume of water.

The unit cost of water transfer company $C_{m}=$ (operating cost $C_{m 1}+$ interest on fluid capital $C_{m 2}$ ) $/ Q$, where operating cost $C_{m 1}=$ engineering maintenance cost $C_{m 11}+$ wage welfare fee $C_{m 12}+$ project management fee $C_{m 13}+$ power cost $C_{m 14}+$ other expenses $C_{m 15}$.

The unit water distribution cost of water plant $C_{r}$ $=\left(\right.$ main business cost $C_{r 1}+$ period cost $C_{r 2}+$ other expenses $\left.C_{r 3}\right) / Q$, in which period cost $C_{r 2}=$ manangement expense $C_{r 21}+$ operation expense $C_{r 22}+$ finanncial expense $C_{r 23}$.

The water price of the water transfer company is $P_{m}$, and that of the water plant is $P$.

The total amount of government subsidies is $S=S_{m}+S_{r}$, that of water transfer companies is $S_{r}=(1-b) S, 0 \leq \mathrm{b} \leq 1 . \mathrm{b}=1$ is to subsidize the water transfer company alone, $b=0$ is to subsidize the water company only, $0<b<1$ is to subsidize the water transfer company and the water supply company.

\subsection{Model Construction and Solution}

\subsubsection{Model Construction}

The profit function of a water transfer company is as follows:

$$
\prod_{\mathrm{m}}=\left(\mathrm{P}_{\mathrm{m}}+\mathrm{bS}-\mathrm{C}_{\mathrm{m}}\right) *\left(\mathrm{Q}_{0}-\alpha \mathrm{P}\right)
$$

The profit function of waterworks is as follows:

$$
\prod_{\mathrm{r}}=\left[\mathrm{P}+(1-\mathrm{b}) \mathrm{S}-\mathrm{P}_{\mathrm{m}}-\mathrm{C}_{\mathrm{r}}\right] *\left(\mathrm{Q}_{0}-\alpha \mathrm{P}\right)
$$

The gross profit function is as follows:

$$
\Pi=\left(\mathrm{P}+\mathrm{S}-\mathrm{C}_{\mathrm{m}}-\mathrm{C}_{\mathrm{r}}\right) *\left(\mathrm{Q}_{\mathrm{o}}-\alpha \mathrm{P}\right)
$$

\subsubsection{Model Solution}

(1) An analysis of the non-cooperative game between the water transfer company and the water plant

In daily life, when the water transfer company determines the water price $P_{m}$, the water company first determines the market price $P_{\text {according to the price of the water }}$ transfer company and other factors, and the two parties form a Stackelberg game relationship. Therefore, the equilibrium solution of the game can be obtained according to the reverse induction method [22].

Formula (7) derives the first derivative of $P, \frac{\partial \prod_{r}}{\partial P}=Q_{0}-2 \alpha P+\alpha P_{m}+\alpha C_{r}-$ $\alpha(1-b) S$. Let $\frac{\partial \prod_{r}}{\partial P}=0$. The optimal water price for a water company in a noncooperative game is obtained as follows:

$$
P^{\text {non cooperation }}=\frac{Q_{0}+\alpha P_{m}+\alpha C_{r}-\alpha(1-b) S}{2 \alpha}
$$


By substituting Formula (9) into Formula (6), the profit function of the water diversion company is obtained as follows:

$$
\prod_{m}^{\text {non cooperation }}=\frac{1}{2}\left[Q_{0}-\alpha P_{m}-\alpha C_{r}+\alpha(1-b) S\right]\left(P_{m}+b S-C_{m}\right)
$$

Formula (10) obtains the first derivative of $P_{m} \frac{\partial \prod_{m}^{\text {non cooperation }}}{\partial P m}=\frac{1}{2}\left(Q_{0}+\alpha C_{m}+\right.$ $\left.\alpha S-2 \alpha b S-2 \alpha P_{m}-\alpha C_{r}\right)$. Let $\frac{\partial \prod_{m}^{\text {non cooperation }}}{\partial P m}=0$, the optimal selling price of the water transfer company is obtained as follows:

$$
P_{m}^{\text {non cooperation }}=\frac{Q_{0}+\alpha C_{m+} \alpha(1-2 b) S-\alpha C_{r}}{2 \alpha}
$$

Substituting Equation (11) into Equation (9), the optimal water price of a water company is as follows:

$$
P^{\text {non cooperation }}=\frac{3 Q_{0}+\alpha C_{m}+\alpha C_{r}-\alpha S}{4 \alpha}
$$

By substituting Equation (12) into Equation (5), the market demand for tap water is obtained as follows:

$$
Q^{\text {non cooperation }}=\frac{1}{4}\left[Q_{0}+\alpha S-\alpha C_{m}-\alpha C_{r}\right]
$$

By substituting Formulas (11), (12), and (13) into formulas (6), (7), and (8), the total profits of water diversion company, water plant, and supply chain are respectively as follows:

$$
\begin{aligned}
\prod_{m}^{\text {non cooperation }} & =\frac{\left[Q_{0}+\alpha S-\alpha C_{m}-\alpha C_{r}\right]^{2}}{8 \alpha} \\
\prod_{r}^{\text {non cooperation }} & =\frac{\left[Q_{0}+\alpha S-\alpha C_{m}-\alpha C_{r}\right]^{2}}{16 \alpha} \\
\prod^{\text {non cooperation }} & =\frac{3\left(Q_{0}+\alpha S-\alpha C_{m}-\alpha C_{r}\right)^{2}}{16 \alpha}
\end{aligned}
$$

The derivative of Equation (12) to $\mathrm{S}$ is obtained $\frac{\partial P^{\text {non cooperation }}}{\partial S}=-\frac{1}{4}<0$. That is, the price of waterworks will decrease with the increase in government subsidies. Formula (13) derives $\mathrm{S}$ and obtains $\frac{\partial \text { non cooperation }}{\partial S}=\frac{\alpha}{4}>0$, that is, the demand for tap water will increase with the increase in government subsidies.

(2) An analysis of the cooperative game between the water transfer company and the water plant

Formula (8) derives the first derivative of price $\mathrm{p}, \frac{\partial \Pi}{\partial P}=Q_{0}+\alpha C_{m}+\alpha C_{r}-2 \alpha P-$

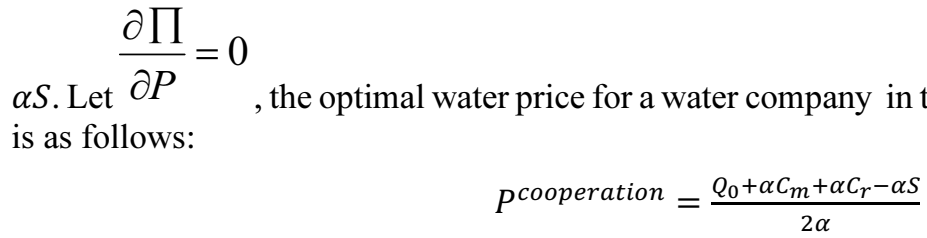

Substituting Formula (17) into Formula (5) to obtain the amount of tap water required in the case of cooperation:

$$
Q=\frac{1}{2}\left(Q_{0}-\alpha C_{m}-\alpha C_{r}+\alpha S\right)
$$

Substitute Formula (17) into Formula (6), and the profit of the water diversion company in the case of cooperation is as follows:

$$
\prod_{m}^{\text {cooperation }}=\frac{1}{2}\left(Q_{0}-\alpha C_{m}-\alpha C_{r}+\alpha S\right)\left(P_{m}-C_{m}+b S\right)
$$


Substituting Formulas (17) and (18) into Formula (8), the overall optimal profit of the two parties is as follows:

$$
\Pi^{\text {cooperation }}=\frac{\left(Q_{0}+\alpha S-\alpha C_{m}-\alpha C_{r}\right)^{2}}{4 \alpha}
$$

From Equation (20) minus Equation (16): $\prod^{\text {cooperation }}-\Pi^{\text {non cooperation }}=$ $\frac{\left(Q_{0}+\alpha S-\alpha C_{m}-\alpha C_{r}\right)^{2}}{16 \alpha}>0$. By subtracting Formula (13) from Equation (18), the following can be obtained: $Q^{\text {cooperation }}-Q^{\text {non cooperation }}=\frac{1}{4}\left(Q_{0}+\alpha S-\alpha C_{m}-\alpha C_{r}\right)>0$. From Equation (17) minus Equation (12) : $P^{\text {cooperation }}-P^{\text {non cooperation }}=-\frac{1}{4}\left(Q_{0}+\right.$ $\left.\alpha S-\alpha C_{m}-\alpha C_{r}\right)<0$.

Therefore, the overall profit and supply of the cooperative water supply company and the water diversion company are greater than those of the non-cooperative water supply company, and the price of the cooperative water supply plant is lower than that of the non-cooperative water supply company.

Formula (17) derives $S$ and obtains $\frac{\partial P^{\text {cooperation }}}{\partial S}=-\frac{1}{2}<0$, that is, the price of water plants decreases with the increase of government subsidy and the rate of reduction is faster than that under non-cooperation. Formula (18) derives $\mathrm{S}$ and obtains $\frac{\partial Q^{\text {cooperation }}}{\partial S}=\frac{\alpha}{2}>0$, that is, the demand for tap water increases with the increase of government subsidies and the rate of increase is faster than that under noncooperation.

(3) Profit distribution of cooperative game based on the Shapley value method

When water companies and water plants cooperate, the distribution of the overall profit benefit is very important. This paper uses the Shapely value method to distribute the overall profit of the supply chain. The expression of the Shapley value method described earlier is as follows:

$$
\varphi_{i}(v)=\sum_{X \subseteq N} \frac{(|X|-1) !(n-|X|) !}{n !}[v(X)-v(X-\{i\})], \forall i \in N
$$

For the supply chain of water diversion project, $\mathrm{n}=2$, the subset of water diversion company includes $X_{m}=$ wwater diversion company $\}, X_{m r}=\{$ water diversion company, water supply company $\}$, and the subset of water supply company includes $X_{r}=\{$ water supply company $\}$ and $X_{r}=$ \{water diversion company, water supply company $\}$. In the case of $X_{m|=1,|} X_{r|=1,|} X_{m r \mid=2 \text {, the profit allocation values of the }}$ water diversion company and the water supply plant are as follows:

$$
\begin{gathered}
\varphi_{m}(v)=\frac{(1-1) !(2-1) !}{2 !}\left[v\left(X_{m}\right)-0\right]+\frac{(2-1) !(2-2) !}{2 !}\left[v\left(X_{m r}\right)-v\left(X_{r}\right)\right] \\
\varphi_{r}(v)=\frac{(1-1) !(2-1) !}{2 !}\left[v\left(S_{r}\right)-0\right]+\frac{(2-1) !(2-2) !}{2 !}\left[v\left(X_{m r}\right)-v\left(X_{m}\right)\right]
\end{gathered}
$$

At this time, $v\left(X_{m}\right)=\prod_{m}^{\text {non cooperation }}, v\left(X_{m r}\right)=\prod^{\text {cooperation }}$, and $=\prod_{r}^{\text {non cooperation }}$. The profit distribution values of the water transfer company and the tap water plant are obtained by substituting Formulas (14), (15), and (20) for Formulas (21) and (22). 


$$
\begin{aligned}
& \prod_{m}^{\text {cooperation }}=\phi_{m}(v)=\frac{1}{2} \prod_{m}^{\prime}+\frac{1}{2}\left[\prod^{\text {cooperation }}-\prod_{r}^{\prime}\right]=\frac{5\left(Q_{0}+\alpha S-\alpha C_{m}-\alpha C_{r}\right)^{2}}{32 \alpha} \\
& \prod_{r}^{\text {cooperation }}=\phi_{r}(v)=\frac{1}{2} \prod_{r}^{\prime}+\frac{1}{2}\left(\prod^{\text {cooperation }}-\prod_{m}^{\prime}\right)=\frac{3\left(Q_{0}+\alpha S-\alpha C_{m}-\alpha C_{r}\right)^{2}}{32 \alpha}
\end{aligned}
$$

The water transfer company and the water supply company cooperate to determine the outlet price of tap water so that the profits of both parties are equal to the profits allocated during the cooperation. Therefore, Formulas (23) and (19) are equal and the water price of the water transfer company under the cooperation situation is as follows:

$$
P_{m}^{\text {cooperation }}=\frac{5 Q_{0}-5 \alpha S+11 \alpha C_{m}+5 \alpha C_{r}}{16 \alpha}
$$

\section{Numerical Simulation and Case Analysis}

In this paper, data on the water price system of the water diversion project of Tao River are taken as an example to carry out an example analysis (Luo,2016) [20].

According to the literature (Luo, 2016) [20], the incomplete cost of water distribution per unit of water transfer companies and water plants (specifically the farmers' water users' association) and the bearing capacity and demand of agricultural water are shown in Table 3.

Table 3. Cost and demand datasheet of the Tao River Diversion Project $\left(\mathrm{RMB} / \mathrm{m}^{3}\right)$.

\begin{tabular}{cccc}
\hline & $\begin{array}{c}\text { Unit Incomplete Cost of } \\
\text { Yintao Company }\end{array}$ & $\begin{array}{c}\text { Unit Water Distribution Cost of } \\
\text { Farmer Water User Association }\end{array}$ & $Q_{0}\left(10000 \mathrm{~m}^{3}\right)$ \\
& $c_{m}\left(\mathrm{RMB} / \mathrm{M}^{3}\right)$ & $c_{r}\left(\mathrm{RMB} / \mathrm{M}^{3}\right)$ & 4976 \\
\hline value & 0.28 & 0.02 & 4907 aximum Demand \\
\hline
\end{tabular}

Data source: the cost is based on the data from Luo Jinren's study on the water price system of multi-objective water diversion project from the perspective of the supply chain, and the maximum demand is based on the demand forecast data in 2019 from the feasibility report of Taohe River Diversion Project.

Assuming $\alpha=1000, S$ takes $0,0.06$, and 0.1 , respectively. The above data are

\begin{tabular}{|c|c|c|c|c|c|c|}
\hline$S=0$ & $\begin{array}{l}P_{m} \\
\left(\mathrm{RMB} / \mathrm{m}^{3}\right)\end{array}$ & $\begin{array}{l}P \\
\left(\mathrm{RMB} / \mathrm{m}^{3}\right)\end{array}$ & $\begin{array}{l}\prod_{m} \\
(10000 \mathrm{RMB})\end{array}$ & $\begin{array}{l}\prod_{r} \\
(10000 \mathrm{RMB})\end{array}$ & $\begin{array}{l}\prod \\
(10000 \mathrm{RMB})\end{array}$ & $\begin{array}{l}Q \\
\left(10000 \mathrm{~m}^{3}\right)\end{array}$ \\
\hline $\begin{array}{l}\text { Non } \\
\text { cooperation }\end{array}$ & 2.62 & 3.81 & 2733.12 & 366.56 & 4099.68 & 1169 \\
\hline cooperation & 0.97 & 2.64 & 3416.40 & 2049.84 & 5466.24 & 2338 \\
\hline
\end{tabular}
substituted into the model solution and the calculation results are shown in Tables 4-6.

Table 4. Water price profit calculation table 1 of the water diversion project without subsidy. 
Table 5. Water price profit calculation table of water diversion project when the subsidy amount is $0.06 \mathrm{RMB} / \mathrm{m}^{3}$.

\begin{tabular}{|c|c|c|c|c|c|c|}
\hline \multirow{3}{*}{$\begin{array}{l}\text { Calculation } \\
\text { Items }\end{array}$} & \multicolumn{6}{|l|}{$S=0.06$} \\
\hline & \multicolumn{2}{|l|}{$b=1$} & \multicolumn{2}{|l|}{$b=0$} & \multicolumn{2}{|l|}{$b=0.5$} \\
\hline & $\begin{array}{l}\text { Non } \\
\text { Cooperation }\end{array}$ & Cooperation & $\begin{array}{l}\text { Non } \\
\text { Cooperation }\end{array}$ & Cooperation & $\begin{array}{l}\text { Non } \\
\text { Cooperation }\end{array}$ & Cooperation \\
\hline $\begin{array}{l}P_{m} \\
\left(\mathrm{RMB} / \mathrm{m}^{3}\right)\end{array}$ & 2.59 & 0.92 & 2.65 & 0.98 & 2.62 & 0.95 \\
\hline$P_{\left(\mathrm{RMB} / \mathrm{m}^{3}\right)}$ & 3.79 & 2.61 & 3.79 & 2.61 & 3.79 & 2.61 \\
\hline $\begin{array}{l}\prod_{m} \\
(10000 \mathrm{RMB})\end{array}$ & 2803.7 & 3504.64 & 2803.71 & 3504.64 & 2803.71 & 3504.64 \\
\hline $\begin{array}{l}1 I_{r} \\
(10000 \mathrm{RMB})\end{array}$ & 1401.8 & 2102.78 & 1401.86 & 2102.78 & 1401.86 & 2102.78 \\
\hline $\begin{array}{l}11 \\
(10000 \mathrm{RMB})\end{array}$ & 4205.57 & 5607.42 & 4205.57 & 5607.42 & 4205.57 & 5607.42 \\
\hline$Q_{\left(10000 \mathrm{~m}^{3}\right)}$ & 1169.3 & 2338.6 & 1169.3 & 2338.6 & 1169.3 & 2338.6 \\
\hline
\end{tabular}

Table 6. Water price profit calculation table of the water transfer project when the subsidy amount is 0.1 $\mathrm{RMB} / \mathrm{m}^{3}$.

\begin{tabular}{|c|c|c|c|c|c|c|}
\hline \multirow{3}{*}{$\begin{array}{l}\text { Calculation } \\
\text { Items }\end{array}$} & \multicolumn{6}{|l|}{$S=0.1$} \\
\hline & $b=1$ & & $b=0$ & & $b=0.5$ & \\
\hline & $\begin{array}{l}\text { Non } \\
\text { Cooperation }\end{array}$ & Cooperation & $\begin{array}{l}\text { Non } \\
\text { Cooperation }\end{array}$ & Cooperation & $\begin{array}{l}\text { Non } \\
\text { Cooperation }\end{array}$ & Cooperation \\
\hline$P_{m\left(\mathrm{RMB} / \mathrm{m}^{3}\right)}$ & 2.57 & 0.90 & 2.67 & 1.00 & 2.62 & 0.95 \\
\hline$P_{\left(\mathrm{RMB} / \mathrm{m}^{3}\right)}$ & 3.78 & 2.59 & 3.78 & 2.59 & 3.78 & 2.59 \\
\hline $\begin{array}{l}1 \mathbf{l}_{m} \\
(10000 \mathrm{RMB})\end{array}$ & 2851.27 & 3564.09 & 2851.27 & 3564.09 & 2851.27 & 3564.09 \\
\hline $\begin{array}{l}\prod_{r} \\
(10000 \mathrm{RMB})\end{array}$ & 1425.64 & 2138.45 & 1425.64 & 2138.45 & 1425.64 & 2138.45 \\
\hline & 4276.91 & 5702.54 & 4276.91 & 5702.54 & 4276.91 & 5702.54 \\
\hline$Q_{\left(10000 \mathrm{~m}^{3}\right)}$ & 1169.5 & 2339 & 1169.5 & 2339 & 1169.5 & 2339 \\
\hline
\end{tabular}

From the perspective of supply quantity, when $S=0$, the Q under non-cooperation and cooperation are $1169\left(10,000 \mathrm{~m}^{3}\right)$ and $2338\left(10,000 \mathrm{~m}^{3}\right)$, respectively. When $S=0.1$, the Q under non-cooperation and cooperation are $1169.3\left(10,000 \mathrm{~m}^{3}\right)$ and $2338.6(10,000$ $\left.\mathrm{m}^{3}\right)$, respectively, the $\mathrm{Q}$ under non-cooperation and cooperation are $1169.5\left(10,000 \mathrm{~m}^{3}\right)$ and $2339\left(10,000 \mathrm{~m}^{3}\right)$, respectively, which indicates that the greater the $\mathrm{S}$, the greater the 
Q. When $S$ is under certain conditions, no matter how much b is taken, Q is always stable and $\mathrm{Q}$ under cooperation is always greater than that under non-cooperation.

From the point of view of water price, $\mathrm{P}$ always decreases with the increase of $\mathrm{S}$,

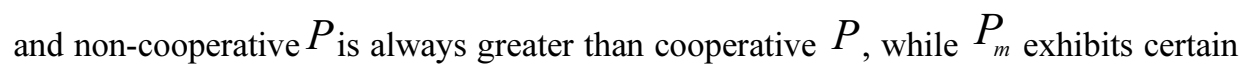
fluctuation with the change of $b$. Taking $\mathrm{S}=0.06$ as an example, we can see that $\mathrm{P}$ stays at 3.79 and 2.61 under cooperation and non-cooperation, respectively, while $P_{m}$ is 2.65 and 0.98 at $b=0,2.62$ and 0.95 at $b=0.5$ and 2.59 and 0.92 at $b=1$. Under a certain condition of $\mathrm{S}$, the higher the $\mathrm{b}$ is, the lower $P_{m}$ is, and under non-cooperation $P_{m}$ is always greater than under cooperation.

From the point of view of profit distribution, with the change of $S$ from 0 to 0.1 , the total supply chain profit $\Pi$, the profit $\prod_{m}$ of the water transfer company, and the profit $\Pi_{r}$ of the water plant are all increasing. When $S$ under certain conditions, $b$ takes different values, there will always be $\prod^{\text {cooperation }}>\prod^{\text {non cooperation }}, \prod_{m}^{\text {cooperation }}>$ $\prod_{m}^{\text {cooperation }}, \prod_{r}^{\text {cooperation }}>\prod_{r}^{\text {cooperation }} . \prod, \prod_{m}$ and $\prod_{r}$ are stable because when $\mathrm{b}=0$ increases to $\mathrm{b}=1, P_{m}$ is gradually reduced, thereby maintaining the stability of the internal profit distribution.

\section{Conclusion}

Government subsidy and profit distribution in the supply chain have been among the hot topics in recent years. In the case of low water price tolerance in underdeveloped areas, how to introduce government subsidies to improve water supply and allocate profits in the supply chain are the keys to maintaining a stable and sustainable operation of water transfer projects. In this paper, the model of non-cooperation game and cooperation in the secondary supply chain composed of water transfer company and waterworks is constructed and solved. The water supply, pricing, and profits of the two parties are compared after receiving subsidies.

The results show that with the increase in subsidy amount, the optimal water supply quantity of water diversion project and the profit of all parties are increased, the water price of water plant is reduced, and the water price of water transfer company is also affected by the government subsidy strategy, thereby indicating instability. When the subsidy amount is fixed, the water price of the water plant becomes stable, and the water transfer company can adjust its price according to the subsidy proportion through its dominant position. Regardless of whether the government subsidizes the company, the total profit under cooperation is greater than that under non-cooperation. The profit distribution result based on the Shapley value distribution model can also cause all parties' share profits to become larger than that under non-cooperation, which not only satisfies individual rationality but also the overall rationality and achieves Pareto optimality.

The above conclusion is based on a single water transfer company and a single water plant as the research object. However, the actual situation of the water transfer project is 
that a water transfer company faces a complex supply chain network formed by many water plants and farmers' water users' associations. The article also has its limitation in some parameter assumptions. Whether the conclusion is consistent with the supply chain subsidy of the water transfer project requires further study.

\section{References}

[1] Tabitha M. Fisheries subsidies in China,Quantitative and qualitative assessment of policy coherence and effectiveness. Marine Policy. 2016; 68:74-82.

[2] Lihua H, Liyan $\mathrm{CH}$. The incentive effects of different government subsidy policies on green builings. Renewable and Sustainable Energy Reviews.2021; 135:110123.

[3] Dana M, Masayoshi N. Worth the wait: The impact of government funding on hospital emergency waiting times. Health Policy. 2020; 124:1340-1344.

[4] Dongmin K, Shasha L, Yanan W. Market competition, property rights and government subsidies. Economic Res. J. 2003; 2: 55-67.

[5] Hu RC, Zeng WQ, Liu L. A study on the effect of provincial and industry differences of government subsidies-ake listed companies in 6 provinces in Central China as an example. Chinese J. Manage. Sci.2014; S1: 255-266.

[6] Wang HJ, Li QY, Liu F. Government subsidies: emergency or poverty relief: Empirical Evidence from a sample of loss making companies. Nankai Business Review. 2015; 18(5): 42-53.

[7] Dongmin K, Tianshang L. Has the government subsidy improved the company's performance and social responsibility. Securities Market Herald. 2014; 6: 26-31.

[8] Wu CS, Qian SL, Zhang LJ. The impact of government subsidies on the performance of manufacturing enterprises. Commercial Res. 2015; 456: 9-16.

[9] Gen Q, Hu RX. An analysis on the influencing factors of enterprises receiving government subsidies an empirical study based on industrial enterprise database. J. Audit \& Economics. 2013; 6: 86-95.

[10] Wu Q, Ren HB, Gao WJ, Ren XJ, Lao CS. Profit allocation analysis among the distributed energy network participants based on Game-theory. Energy. 2017; 118: 783-794.

[11] Maryam B. A game theoretic approach for pricing petroleum and determining investors' production volume with the consideration of government and intermediate producers. Sustainable Energy Technologies and Assessments. 2020; 42: 100825.

[12] Zhu QH, Dou YJ. Game model of green supply chain management based on government subsidy analysis. J. Manage. Sci. 2011; 14(6): 86-95.

[13] Lu HX. Study on the pricing decision of supply chain of household electrical appliances industry with government subsidies. Modern Business. 2015; 27: 13-15.

[14] Li YD, Zhao DZ, Xia LJ. Government subsidy strategy under vertical emission reduction cooperation of low-carbon supply chain. Operations Research and Management Science. 2014; 4: 1-11.

[15] Zhang XL, Wang JJ. Analysis of government subsidies in the supply chain of new energy vehicles based on Shapley value method. Soft Science. 2015; 29(9): 54-58.

[16] Wang HM, Zhang L, Yang W. Pricing model of water resources supply chain in the east line of South to North Water Diversion Project. J. Hydraul. Eng. 2008; 39(6): 758-762.

[17] Chen ZS. Study on supply chain coordination mechanism of South to North Water Diversion from the perspective of economic benefits and social responsibility. Resources Science. 2013; 35(6): 1245-1253.

[18] Wu LZ, Bai T, Huang Q. Tradeoff ananlysis between economic and ecological benefits of the inter basin transfer project under changing environment and its operation rules. J. Cleaner Production. 2020; 248:119294.

[19] Wang XZ, Wang YR. Study on the reasonable standard and charging system of water price for the central line of South to North Water Transfer Project. J Economics Water Res. 2015; 1:18-22.

[20] Jinren L. Research on water price system of multi-objective water transfer project-Analysis Based on the perspective of water resources supply chain. Price:Theory and Practice.2016; 5:61-64

[21] Jinren L. Basic research on the construction of the mechanism of balancing the interests of stakeholders in water diversion projects- take "Tao River Diversion Project" as an example. Lanzhou University, 2010.

[22] Weiying Z. Game theory and information economics, Shanghai people's Publishing House, Shanghai, 1996. 